\title{
The Process of Acquiring Declarative Sentence on Aphasia
}

\author{
Muhammad Muzakky, Fahriani, Meli Aulia Utami \\ UIN Syarif Hidayatullah Jakarta
}

Zakkazakky08.mm@gmail.com, Fahriany@uinjkt.ac.id, Meli_utami19@mhs.uinjkt.ac.id

\begin{abstract}
The present study investigates the process of acquiring declarative sentences in adult aphasia. This study seeks to address the question of how the process of an aphasia to acquire declarative sentences. Using a case study, the process of interview was implemented to explore the subject's response toward this issue. The subject is an adult Indonesian speaker who is 69 years old. The data were obtained from interviews and documents. The interview section was used to explore the process of acquiring declarative sentences, and the documents were used to check the validity of the interview. The data analysis of acquiring declarative sentences showed: (1) the process of acquiring the language on an adult is through behaviorist theory that consists of subject's routinizes in reading books, newspapers, and comics. (2) In adult language learners, the duration of acquiring the language is not too long and challenging. The subject takes a significant effort to deal with various activities, and it is the characteristic of an adult in acquiring the language. (3) In the construction of declarative sentences, the subjects could produce six sentences correctly and no grammar errors. He also could interact with others through those sentences. The challenge is on the way he produces, which is slowly mouth movement. Additionally, we open the gate of future research with pieces of evidence. It was recommended the future research on this study might be conducted in a quantitative method with more adult aphasia involved.
\end{abstract}

Keywords: second language acquisition, aphasia language learner, declarative sentence

\section{INTRODUCTION}

This article aims to demonstrate how an adult who experienced aphasia relearn how to speak and communicate. Since the scope of language is extensive, we will limit it to the acquisition of declar ative sentences. Even though a wide range of research on adult language acquisition is blooming for quite some time, to our knowledge, there is still a little attention of study that focuses on adult aphasia learning process. However, it is vital to remember that not only is this a case study, the objective of this research also only takes a little piece of the whole phenomenon.

Now, talking about learning a language in the adult period, even though researchers have provided extensive analysis on how the age of acquisition is crucial in successfully learning the target language, this effortful and complex process is typically standard. This phenomenon thus paves an excellent opportunity for various self-learning neural developments stimulating in an ecological context. Another study also mentioned that adult language learning has been analyzed by employing artificial languages or categorization tasks that aim to particular skils for example lexical learning (H. Li et al., 2019; Plante et al., 2015).

Due to high level of cognitive skills, better analytical ability, logical thinking, and stable selfmonitoring capacity, some researchers believe that an adult can learn a new language effortlessly (Mohamad Nor \& Rashid, 2018). In contrast, some others also argued that adult must confront some factors that can discourage them to acquire the target language. Adult learners of a second or additional language (Ln) need to acquire syntactic structures, lexical items, morphological paradigms, and phonological properties in order to communicate in the new language successfully (Schepens et al., 2020). The process of learning these abilities is dynamic. There are cases where even after several years of exposure towards the target language, adult learners are still unable to earn language proficiency like a native speaker.

Previous studies have shown a specific interest in adult language acquisition as L2 or Ln in a variety of focus such as the impact of L1 background (Artieda, 2017), learners' distinguish aptitude (Kidd et al., 2018; Saito, 2017), a biological factor especially age (Abutalebi \& Clahsen, 2018; Arnon et al., 2017; Deng \& Zou, 2016), and environment that supports social interaction (Montrul, 2020). These findings are evidence that adult language learners' barrier is not always dependent on their cognitive skills. Even so, research on an adult who learns a language due to aphasia, to our knowledge, has never been discussed before.

This study sheds light on adult language learners' process after their aphasia to acquire the declarative sentence as a learnable aspect of language acquisition not already placed in the input sy stem of the human brain. Due to memory loss, they have to learn the language repeatedly as if they were just born. This background is rare and exciting to fill in the gap of how an adult learns language without a prior language ability. Interlanguage usually occurs when learning a new language due to their L1 
knowledge. However, with this background, interlanguage stands no chance to happen. Thus, it will reveal the factors that can prevent adult learners from acquiring a new language.

Studies have found that agrammatic aphasia patients are having an issue in interpreting complex declarative sentences. (Salis \& Edwards, 2008). Another study also states that various studies indicate how aphasia subjects have success and failure patterns in understanding various structure types (Berndt et al., 1997). A declarative sentence is a sentence that is commonly used to make a statement or to declare an idea. It is aimed to state a fact or argument in a declarative mood. This sentence type structure can be various, but the least minimal is subject followed by the predicate. Like any other sentence formula, it consists of semantic and syntactic structures. Polar questions are derived from declarative sentences by auxiliary movement. For instance, declarative with progressive verbs place the auxiliary "is" before the verb "playing" as in the sentence "The boy is playing." The declarative sentence is one of the sentence structures that is commonly analyzed by researchers in another type of brain-injury as well (Salis \& Edwards, 2008).

In the case of aphasic patient, they have difficulty not only in understanding the sentence but also producing (Berndt et al., 1997; Schwartz et al., 1987). Sentence production is a compound process that requires various stages such as conceptualization, phonological selection, and syntactic composition (Sung et al., 2018). The cognitive resource is one of the required factors as it will be engaged with syntactic formulas in which its complexity rises. Also, Chomsky (1957) stated that the individual's input does not explain the syntactic knowledge that supports the correct structure.

With that being said, in this paper, our purpose is drawn into this research question: how an adult who experienced aphasia has to relearn or acquire declarative sentences. Finally, we will critically demonstrate the stages in which the subject has to go through in learning declarative sentences with regards to this research question.

\section{MATERIALS AND METHOD}

This study was executed with a case study research design to explore the process of acquiring declarative sentences. Descriptive qualitative performed to describe the existing phenomenon as naturally as possible. The critical point of this method is that the researchers can only report what happens without having the control to manipulate the variables. In a case study, it is an intensive exploration about a person to get generalization of the research focus. Then, to explore the adult aphasia process on declarative sentence, one adult speaking Indonesian language was recruited as the subject of the research. He is 69 years old who got Aphasia five years ago. At that time, he got a seriou s accident with his brain which caused he forgot how to speak and arrange some proper sentences. Then, he tried to reacquire the language including declarative sentence which becomes the focus of this study.

To gather the data, this study used interviews and documentaries as the instrument of research. The interview section is used to explore subjects' responses toward the process of acquiring a declarative sentence. It was recorded and transcribed to know the subjects' responses to the process. Documents were collected to support the data from the interview. This is also used to check the validity of the research or triangulation of qualitative research.

Then, to analyze the data, the theory from Cresswell (2012) was implemented. First, the recorded interview was transcribed. It was then read to get the general sense of the data, which is used to answer the research question related to acquiring declarative sentences on adults. After that, it is described in narrative description. The data were interpreted based on the theories of some scholars, personal views, making comparisons between the findings and the literature review.

\section{RESULTS AND DISCUSSION}

\subsection{THE PROCESS OF ACQUIRING LANGUAGE}

The subject is asked about acquiring language during his treatment on Aphasia and after he can remember well. The subject says that to acquire a language, he tries to do reading activities. He reads the newspaper every morning, some books, and also comics. For adults, the main resource of new vocabulary comes from several contexts, including reading (Ma et al., 2015). Reading is one of possible sources where a learner can acuqire word meanings. Some scholars hold the view that in the adolescent learners, L1 literacy improvement through reading can positively benefit the L2 achievement (Artieda, 2017). This activity is done individually and regularly, which becomes his habit. It is supported by Behaviorism theory, which strives to explain that the process of habit formation is the key to L2 
acquisition of linguistic structures (Powell et al., 2012). Behaviorists believe that learning is an observable behavior, through some stimulus and response through mechanical repetition.

Besides the habits, the subject said that he got treatment from a doctor to speak. Here, the doctor did some instruction such as showing an apple and the subject had to spell a-p-p-l-le. This condition was supported by Sweller (2017), who stated that learning to acquire in adult needs to be effortful since they have to look at the explicit instruction on the part of instructors.

\subsection{LENGTH OF THE PROCESS OF ACQUIRING}

This question aimed to know in the subject's case how long adults with Aphasia could speak well after the tragedy. The subject explained that there are some stages times during the process, which are the first three months is controlling and checkup that in this stage he does read as an interview question number one said, the second is after three months, he is able to enter the office and did some activities such as writing a letter, memo and report where at this stage he could write well also a bit fluent in speaking. It is supported by Bley-Vroman (1989) who proposed that adult second language learning acquisition is not similar to the child language progress as to adult it is more alike to their usual general problem-solving. Moreover, age of acquisition can beneficially impact the learner for example words that are acquired during childhood can give a positive progressing privillage once they become an adult in a variety of lexical and semantic tasks, including sentence processing (Arnon et al., 2017). Earlyacquired words tend to get faster response than later-acquired ones after controlling for adult usage patterns (the word's frequency in adult language).

Furthermore, the subject trains himself by writing a letter and other worksheets in his office. Zhang, Q., \& Min, G. (2019) point out that the key factors affecting writing outcomes are participants' characteristics. While in this case, the subject got effortful to do his language proficiency.

\subsection{DeClarative SENTENCE THAT COULD BE PRODUCED}

This question sheds light on how many sentences could be produced during the process of acquiring. Then from the data, the subject could construct six declarative sentences during the three months process of controlling; below are the constructed sentences:

$\begin{array}{ll}\text { - } & \text { I ride blue Vespa motorcycle } \\ \text { - } & \text { I wear a cap } \\ \text { - } & \text { I use gla ss shoes } \\ \text { - } & \text { I weargrey pans } \\ \text { - } & \text { I turn right to go home } \\ & \text { I fell in front of themosque }\end{array}$

Generally, the sentence is constructed well, and he tries to state some ideas. Also, he used the sentence to answer the question from the doctor. It is supported by Shopen (2007) that says declaratively, the sentence is conventionally used for speech acts such as claiming, stating, reporting, complaining, and bragging. Moreover, the theory of universal grammar by Chomsky (1976) stated that biologically humans are born to learn a language since they are provided with the language faculty or Language Acquisition Device (LAD).

\subsection{ERROR ANALYSIS OF THE SENTENCE DURING THE PROCESS OF ACQUIRING}

Data shows that there is no error analysis, such as in the interview question number three that he is able to utter six sentences in a good construction such as:

- I ride blue Vespa motorcycle

- I weara cap

- I use glass shoes

- I weargrey pans

- I turn right to go home

- I I fell in front of themosque

The sentences are good grammatically, but the barrier is on the way he produces them is too slow. He knows what he wants (the words are in the brain) to say, but it is challenging to produce. According to Kresen in Latif (2015) an adult learner is a formal thinker who is able to utilize formal operations such as conscious grammar, meta-awareness, and general abstract rules of language. Vygotsky (1978) believes that language learning or acquisition only happens when the learner tries to communicate with 
somebody who has higher proficiency such as their teachers or friends who achieved higher fluency in the target language. In this case, the subject constructs sentence well due to his habits to read and interact with people such as the doctor and his family.

\subsection{DiscusSION}

The following discussions are based on the research focus. There is the process of acquiring declarative sentences in adults. Here, the subject was asked about acquiring language, the length of the process, how to construct a declarative sentence, and the error analysis of declarative sentences. The subject explained that there are some factors to provoke him to acquire the language. There are analyzing book offices, reading the newspaper regularly every morning, and reading comics to entertain him. Ade-Ojo (2019) suggests that the seeming insensitivity of adult literacy provisions to the process of acquiring language, the ideological as autonomous perceptions of literacy.

Those activities became his habit to acquire language. This condition shows that the theory of behaviorism, which says learning as the acquisition of a set of structures through the process of habit formation (Powell et al., 2012), on language acquisition is proven. In adulthood, speech sounds' better behavioral performance is related to tremendous success learning foreign language vocabulary; nonnative speech perception abilities may act as a "gatekeeper" to the initial stages of foreign language learning (Qi et al., 2019). In sum, the behavior and the richness of literacy are the main factors to acquire the language in adult.

What is more, adults' self-monitoring ability in the process of acquiring language is powerful (Deng \& Zou, 2016). The subject use reading as learning strategies to carry out autonomous learning without any force from others. In other words, He has a strong self-monitoring. Language control is a crucial part of the language learning process, involving the recruitment of extra resource when comprehension is effortful (Gurunandan et al., 2019).

Furthermore, the subject answered on the acquisition period is through controlling in 3 months and practicing in 7 months.

During the controlling stage, the subject tries to acquire the language by reading some texts, writing, and interacting with people. It is on Bley-Vroman's (1989) theory that proposed adult second language learning acquisition more similar to general adult problem-solving. The subject also tries to write something such as reports and notes. As Chik and Ho (2017) stated that the act of repeatedly writing things down using pen and paper is the best way to remember the new words adult learn. In addition, during this time, the subject got some instruction from the doctor to pronounce and speak some words. Here, an adult need to be effortful since they have to look at the explicit instruction on the part of instructors (Sweller, 2017).

In terms of a declarative sentence, the subject responds to some sentences. He can speak without having any grammatical mistakes. Deng et al. suggested that adult L2 speakers with high morphological cognition are sensitive to rule violations and apply error. This situation also indicates that the theory of Universal grammar proposed by Chomsky says every human is biologically equipped to learn a language using the language faculty other Language Acquisition Device (LAD). In the case of tricky words on declarative sentences, advanced learners have already developed a sensitivity to morphological information (Kimppa et al., 2019), while such knowledge is weak in beginners.

The subject also could use the sentence to interact because the adult brain displays significant neuroplasticity in response to social interaction (P. Li \& Jeong, 2020). Besides, the declarative sentences can be used for representative, declaration, commissure, expressive, and directive speech acts. For example, from the data the subject says "I wear a cap," the speaker states the function of speech act as stating that he has just worn a cap. Ade-Ojo et al. (2015) has explored the nature of the social dimension of adult literacy which recognizes literacy as a social practice. Piaget stated that the interaction with the environment and the thereby acquired sensorimotor information initially drives cognitive development (Vogt et al., 2019). Moreover, the most-immediate environmental pertains can affect the frequency of language used that can help an adult to acquire and process the language better (Kidd et al., 2018).

\section{CONCLUSION}

This research was conducted to pinpoint acquiring the declarative sentence, and it was conducted on an adult apahsia. The conclusion was explained in this part.

The data earned from the research shows: (1) the process of acquiring the language is through behaviorist theory that consists of the subject's routinize in reading books, newspapers, and comics. (2) In adult language learners, the duration of acquiring the language is not too long and challenging. The 
subject takes a significant effort to deal with various activities, and it is the characteristic of adults in acquiring the language. (3) In the construction of declarative sentences, the subjects could produce six sentences correctly and no grammar errors. He also could interact with others through those sentences. The challenge is on the way he produces, which is slowly mouth movement.

Having researched pinpointing the process of acquiring declarative sentences on adult language learners, this research has its limitations. The subject of the research should be enriched in quantity. One single subject is not enough to get valid information on this issue. We cannot provide strong evidence or prediction about whether a similar correlation exists in adults. It might be the other adult language learners' point of view on this term, what they feel and what they do through the process of acquisition.

\section{REFERENCES}

Abutalebi, J., \& Clahsen, H. (2018). Critical periods for language acquisition: New insights with particular reference to bilingualism research. In Bilingualism (Vol. 21, Issue 5, pp. 883-885). https://doi.org/10.1017/S1366728918001025

Ade-Ojo, G., \& Duckworth, V. (2015). The consolidation of an instrumental value position: The moser committee. In Adult Literacy, Policy and Practice: From Intrinsic Values to Instrumentalism (pp. 65-100). Palgrave Macmillan. https://doi.org/10.1057/9781137535115

Ade-Ojo, G. O., \& Duckworth, V. (2019). Forms of institutionalised symbolic violence and resistance in the journey of a cohort of adult literacy learners. International Journal of Educational Research, 98, 336-344. https://doi.org/10.1016/j.ijer.2019.08.008

Arnon, I., McCauley, S. M., \& Christiansen, M. H. (2017). Digging up the building blocks of language: Age-of-acquisition effects for multiword phrases. Journal of Memory and Language, 92, 265280. https://doi.org/10.1016/j.jml.2016.07.004

Artieda, G. (2017). The role of L1 literacy and reading habits on the L2 achievement of adult learners of English as a foreign language. System, 66, 168-176. https://doi.org/10.1016/j.system.2017.03.020

Berndt, R. S., Mitchum, C. C., \& Wayland, S. (1997). Patterns of sentence comprehension in aphasia: A consideration of three hypotheses. Brain and Language, 60(2), 197-221. https://doi.org/10.1006/brln.1997.1799

Bley-Vroman, R. W. (1989). What is the logical problem of foreign language learning? In S. Gass \& J. Schachter (Eds.), Linguistic perspectives on second language acquisition (pp. 41-68). Cambridge University Press.

Chik, A., \& Ho, J. (2017). Learn a language for free: Recreational learning among adults. System, 69, 162-171. https://doi.org/10.1016/j.system.2017.07.017

Chomsky, N. (1957). Syntacric strucfures. Moutin.

Chomsky, N. (1976). Reflections on language. Pantheon.

Creswell, J. W. (2012). Planning, Conducting, and Evaluating Quantitative and Qualitative Research. In Pearson (4th ed., Vol. 66). Educational Research, Pearson.

Deng, F., \& Zou, Q. (2016). A study on whether the adults' second language acquisition is easy or notFrom the perspective of children's native language acquisition. Theory and Practice in Language Studies, 6(4), 776. https://doi.org/10.17507/tpls.0604.15

Gurunandan, K., Carreiras, M., \& Paz-Alonso, P. M. (2019). Functional plasticity associated with language learning in adults. NeuroImage, 201(July), 116040. https://doi.org/10.1016/j.neuroimage.2019.116040

Kidd, E., Donnelly, S., \& Christiansen, M. H. (2018). Individual differences in language acquisition and processing. Trends in Cognitive Sciences, 22(2), 154-169. https://doi.org/10.1016/j.tics.2017.11.006

Kimppa, L., Shtyrov, Y., Hut, S. C. A., Hedlund, L., Leminen, M., \& Leminen, A. (2019). Acquisition of L2 morphology by adult language learners. Cortex, 116, 74-90. https://doi.org/10.1016/j.cortex.2019.01.012

Latif, A., \& Binti, A. (2015). A study on English language anxiety among adult learners in Universiti Teknologi Malaysia (UTM). Procedia-Social and Behavioral Sciences, 223-232.

Li, H., Qu, J., Chen, C., Chen, Y., Xue, G., Zhang, L., Lu, C., \& Mei, L. (2019). Lexical learning in a new language leads to neural pattern similarity with word reading in native language. Human Brain Mapping, 40(1), 98-109. https://doi.org/10.1002/hbm.24357

Li, P., \& Jeong, H. (2020). The social brain of language: grounding second language learning in social interaction. Npj Science of Learning, 5(1). https://doi.org/10.1038/s41539-020-0068-7 
Ma, T., Chen, B., Lu, C., \& Dunlap, S. (2015). Proficiency and sentence constraint effects on second language word learning. Acta Psychologica, 159, 116-122. https://doi.org/10.1016/j.actpsy.2015.05.014

Mohamad Nor, N., \& Rashid, R. A. (2018). A review of theoretical perspectives on language learning and acquisition. Kasetsart Journal of Social Sciences, 39(1), 161-167. https://doi.org/10.1016/j.kjss.2017.12.012

Montrul, S. (2020). How learning context shapes heritage and second language acquisition. In The Handbook of Informal Language Learning (pp. 57-74). https://doi.org/10.1002/9781119472384.ch4

Plante, E., Almryde, K., Patterson, D. K., Vance, C. J., \& Asbjørnsen, A. E. (2015). Language lateralization shifts with learning by adults. Laterality, 20(3), 306-325. https://doi.org/10.1080/1357650X.2014.963597

Powell, R. A., Honey, P. L., \& Symbaluk, D. G. (2012). Introduction to learning and behavior. Wadsworth Cengage Learning.

Qi, Z., Han, M., Wang, Y., de los Angeles, C., Liu, Q., Garel, K., Chen, E. S., Whitfield-Gabrieli, S., Gabrieli, J. D. E., \& Perrachione, T. K. (2019). Speech processing and plasticity in the right hemisphere predict variation in adult foreign language learning. NeuroImage, 192(February), 76-87. https://doi.org/10.1016/j.neuroimage.2019.03.008

Saito, K. (2017). Effects of sound, vocabulary, and grammar learning aptitude on adult second language speech attainment in foreign language classrooms. Language Learning, 67(3), 1-29. https://doi.org/10.1111/lang.12244

Salis, C., \& Edwards, S. (2008). Comprehension of wh-questions and declarative sentences in agrammatic aphasia: The set partition hypothesis. Journal of Neurolinguistics, 21(5), 375-399. https://doi.org/10.1016/j.jneuroling.2007.11.001

Schepens, J., van Hout, R., \& Jaeger, T. F. (2020). Big data suggest strong constraints of linguistic similarity on adult language learning. Cognition, 194. https://doi.org/10.1016/j.cognition.2019.104056

Schwartz, M. F., Linebarger, M. C., Saffran, E. M., \& Pate, D. S. (1987). Syntactic transparency and sentence interpretation in aphasia. Language and Cognitive Processes, 2(2), 85-113. https://doi.org/10.1080/01690968708406352

Shopen, T. (2007). Part of speech system. In T. Shopen (Ed.), Languae Typology and syntactic description, Vol 1: Clause Structure (pp. 3-61). Cambridge University Press.

Sung, J. E., Eom, B., \& Lee, S. E. (2018). Effects of working memory demands on sentence production in aphasia. Journal of Neurolinguistics, 48(March), 64-75. https://doi.org/10.1016/j.jneuroling.2018.03.006

Sweller, J. (2017). Cognitive load theory and teaching English as a second language to adult learners. Contact Magazine, 43(1), 5-10.

Vogt, A., Kaup, B., \& Dudschig, C. (2019). When words are upside down: Language-space associations in children and adults. Journal of Experimental Child Psychology, 186, 142-158. https://doi.org/10.1016/j.jecp.2019.06.001

Vygotsky, L. (1978). Interaction between learning and development. In Mind in society (pp. 79-91). Harvard University Press. 
